\title{
Arsenate removal from aqueous solutions using modified red mud
}

\author{
Shuwu Zhang ${ }^{\mathrm{a}}$, Changjun Liu ${ }^{\mathrm{b}}$, Zhaokun Luan ${ }^{\mathrm{a}, *}$, Xianjia Peng ${ }^{\mathrm{a}}$, \\ Haijing Ren ${ }^{\mathrm{a}}$, Jun Wang ${ }^{\mathrm{a}}$ \\ a State Key Laboratory of Environmental Aquatic Chemistry, Research Center for Eco-Environmental Sciences, \\ Chinese Academy of Sciences, P.O. Box 2871, Beijing 100085, PR China \\ b Shandong Aluminium Co. Ltd., Shandong 255061, PR China
}

Received 14 March 2007; received in revised form 11 June 2007; accepted 3 July 2007

Available online 17 July 2007

\begin{abstract}
Red mud (RM), a waste tailing from alumina production, was modified with $\mathrm{FeCl}_{3}$ for the removal of arsenate from water. The $\mathrm{RM}$ and modified red mud (MRM) were characterized using scanning electron microscopy (SEM) and X-ray diffraction (XRD) microanalysis. Adsorption of arsenate on modified red mud (MRM) was studied as a function of time, $\mathrm{pH}$, and coexisting ions. Equilibrium time for arsenate removal was $24 \mathrm{~h}$. Solution $\mathrm{pH}$ significantly affected the adsorption, and the adsorption capacity increased with the decrease in $\mathrm{pH}$. Langmuir and Freundlich isotherms equation were used to fit the adsorption isotherms. The Langmuir isotherm was the best-fit adsorption isotherm model for the experimental data. Adsorption capacity of MRM was found to be $68.5 \mathrm{mg} / \mathrm{g}, 50.6 \mathrm{mg} / \mathrm{g}$ and $23.2 \mathrm{mg} / \mathrm{g}$ at pH 6,7 and 9, respectively. $\mathrm{NO}_{3}{ }^{-}$had little effect on the adsorption. $\mathrm{Ca}^{2+}$ enhanced the adsorption, while $\mathrm{HCO}_{3}{ }^{-}$decreased the adsorption. MRM could be regenerated with $\mathrm{NaOH}$, and the regeneration efficiency reached $92.1 \%$ when the concentration of $\mathrm{NaOH}$ was $0.2 \mathrm{~mol} / \mathrm{L}$.
\end{abstract}

(C) 2007 Elsevier B.V. All rights reserved.

Keywords: Red mud; Modified red mud; Arsenate adsorption; Langmuir isotherm; Freundlich isotherm

\section{Introduction}

Arsenate is a widespread toxic contaminant in water and its pollution in ground water has been found in many countries in the world [1]. Human poisoning and death from arsenic have occurred in Taiwan, Bangladesh, India, etc. [2]. Chronic arsenism poses a serious health problem in China also [3]. In 2002, the USEPA lowered the maximum contaminant level (MCL) for arsenic in drinking water from $50 \mu \mathrm{g} / \mathrm{L}$ to $10 \mu \mathrm{g} / \mathrm{L}$. The new MCL was enforced in 2006. The WHO, the European Union, and several other countries also lowered their recommended or required arsenic limit to $10 \mu \mathrm{g} / \mathrm{L}$ in drinking water. As a result of the lower MCL, many methods have been developed to remove excessive arsenate from water, namely, adsorption, coagulation, ion exchange, precipitation, electrolysis, and reverse osmosis [4-8]. Among them, adsorption was regarded as a reliable and economical technique. Many kinds of adsorbents such

\footnotetext{
* Corresponding author. Tel.: +86106284 9150; fax: +861062849198.

E-mail addresses: zhangshuwu@126.com (S.Zhang), Luanzk@ rcees.ac.cn (Z. Luan).
}

as iron oxide-loaded slag [4], Fe-oxide impregnated activated carbon [9], akaganeite [10], red mud [11,12] have been developed for the removal of arsenic. Adsorption will provide an attractive technology if the adsorbent is cheap and ready for use.

Red mud, a waste tailing formed during the production of alumina, causes serious environmental problems due to its high alkalinity and large amount. For every tonne of alumina produced, 0.5-2 tonnes (dry weight) of red mud residues are produced. It is estimated that in china about 10 million tonnes red mud will be produced annually in the near future. The disposal and management of red mud tailing residue constitutes one of the most challenging problems facing the alumina industry [13]. Red mud is composed primarily of particles of iron, aluminium, calcium, silica, titanium oxides and hydroxides. Arsenate is strongly adsorbed on $\mathrm{Fe}, \mathrm{Al}$ and Ti oxides and hydroxides $[4,14,15]$, which are abundant in RM. The use of red mud as an adsorbent for arsenate has been advocated. RM has been found to remove fluoride [16], chromium [17], phosphate [18], dyes [19] from aqueous solution. Altundog investigated the removal of $\mathrm{As}(\mathrm{V})$ from a $10 \mathrm{mg} / \mathrm{L}$ solution using acid-activated red mud and found that the maximum removal reach $96.5 \%$ 
[11]. Genç-Fuhrman removed arsenate effectively using seawater neutralized red mud. The release of metal ions from seawater neutralized red mud during arsenate sorption was also investigated and the results indicated that negligible quantities of the metal ions were released [12].

Here a method is used to modify the red mud with $\mathrm{FeCl}_{3}$. The RM and modified red mud (MRM) are characterized using scanning electron microscopy (SEM) and X-ray diffraction (XRD) microanalysis. The removal of arsenate from aqueous solution using the MRM is studied in batch experiments. The influences of time, initial $\mathrm{pH}$, and coexisting ions on the adsorption capacity are investigated.

\section{Materials and methods}

\subsection{Materials}

The RM used in the study was obtained from Shandong Aluminium Corporation, China. The chemical composition of RM was analyzed through conventional method by the chemical analysis of aluminosilicates [20]. It has the following chemical composition (wt.\%) listed in Table 1 and it shows that RM is primarily a mixture of $\mathrm{Fe}$, $\mathrm{Ti}$ and $\mathrm{Al}$ oxides. The single-point $\mathrm{N}_{2}$ BET method indicated that the specific surface area of a typical RM sample was about $115 \mathrm{~m}^{2} / \mathrm{g}$.

The modification of RM was carried out as follows: RM was sieved and the particles below $177 \mu \mathrm{m}$ were used for modification. Ten grams of powder was added to $1 \mathrm{~L}$ water and $\mathrm{pH}$ of the solution was about 13 . The mixture was stirred at $60 \mathrm{rpm}$ and $0.5 \mathrm{M} \mathrm{FeCl}_{3} \cdot 6 \mathrm{H}_{2} \mathrm{O}$ was added dropwise to the mixture until the $\mathrm{pH}$ reached 5. About $40 \mathrm{~mL} \mathrm{FeCl}_{3} \cdot 6 \mathrm{H}_{2} \mathrm{O}$ was expended. The resulting solution was aged for 1 day and the mixture was centrifuged. The obtained solid was washed with deionised water three times and dried at $105^{\circ} \mathrm{C}$. The MRM was then sieved again, and particles below $177 \mu \mathrm{m}$ obtained were used as adsorbent for the experiments.

\subsection{Instrument}

Arsenate was analyzed on Atomic Fluorescence Spectrometer (AF-610A). The specific surface area of the samples was determined by the BET nitrogen gas sorption method using a Micromeritics ASAP2000V Accelerated Surface Area and Porosimetry. The micrograph and microanalysis of the samples

Table 1

Composition and properties of RM used (wt.\%)

\begin{tabular}{lc}
\hline Constituent & $\%(w / w)$ \\
\hline $\mathrm{SiO}_{2}$ & 13.44 \\
$\mathrm{Fe}_{2} \mathrm{O}_{3}$ & 23.98 \\
$\mathrm{Al}_{2} \mathrm{O}_{3}$ & 12.80 \\
$\mathrm{CaO}+\mathrm{MgO}$ & 13.00 \\
$\mathrm{Na}_{2} \mathrm{O}$ & 6.22 \\
$\mathrm{~K}_{2} \mathrm{O}$ & 0.40 \\
$\mathrm{TiO}_{2}$ & 12.24 \\
$\mathrm{LOI}$ & 16.45 \\
\hline
\end{tabular}

LOI: loss on ignition. were determined using a $30 \mathrm{kV}$ HITACHI S-3000N scanning electron microscope (SEM). X-ray diffraction (XRD) patterns of all samples were obtained with a Rikaku Dmax-RB diffract meter using $\mathrm{Cu} \mathrm{K} \alpha$ radiation at $40 \mathrm{kV}$ and $150 \mathrm{~mA}$ over the $2 \theta$ range of $10-100^{\circ}$.

\subsection{Adsorption and desorption experiments}

All chemicals were of analytical grade and used without further purification. All glassware and sample bottles were soaked in diluted $\mathrm{HCl}$ solution for $24 \mathrm{~h}$ and washed three times with deionised water. All experiments were conducted in duplicate and the mean values were considered. Solutions were prepared from $\mathrm{Na}_{2} \mathrm{HAsO}_{4} \cdot 7 \mathrm{H}_{2} \mathrm{O}$ for $\mathrm{As}(\mathrm{V})$. A $1 \mathrm{~g} / \mathrm{L} \mathrm{As}(\mathrm{V})$ stock solution was prepared by dissolving $4.057 \mathrm{~g} \mathrm{Na}_{2} \mathrm{HAsO}_{4} \cdot 7 \mathrm{H}_{2} \mathrm{O}$ in $1 \mathrm{~L}$ of distilled water. As(V)-bearing water was prepared by diluting As(V) stock solution to given As concentrations with deionised water. The $\mathrm{pH}$ of the solutions was adjusted with either $\mathrm{HCl}$ or $\mathrm{NaOH}$ solution.

Adsorption studies were carried out by shaking $200 \mathrm{~mL}$ of $1 \mathrm{mg} / \mathrm{L} \mathrm{Na} \mathrm{NAsO}_{4} \cdot 7 \mathrm{H}_{2} \mathrm{O}$ solution at $400 \mathrm{rpm}$ with $0.02 \mathrm{~g}$ of MRM in the bottles for $24 \mathrm{~h}$ at room temperature $\left(20 \pm 1^{\circ} \mathrm{C}\right)$, and a background electrolyte of $0.01 \mathrm{M} \mathrm{NaCl}$ was used for all batch experiments. After equilibrium, the solutions were centrifuged at $5000 \mathrm{rpm}$ for $10 \mathrm{~min}$ and the supernatant was taken and analyzed for arsenate. Arsenate adsorbed was calculated as follows:

$q=\frac{\left(C_{0}-C_{\mathrm{e}}\right) V}{M}$

where $q$ is the concentration of the arsenate adsorbed $(\mathrm{mg} / \mathrm{g}), C_{0}$ and $C_{\mathrm{e}}$ are the initial and final concentrations of the arsenate in solution $(\mathrm{mg} / \mathrm{L})$, respectively. $V$ is the solution volume $(\mathrm{L})$ and $m$ is the mass of sorbent $(\mathrm{g})$.

Desorption experiments using $\mathrm{NaOH}$ were carried out. First arsenate was adsorbed according to the same procedure described above. Suspensions were centrifuged after adsorption. The supernatant was decanted and analyzed for arsenate. Then $50 \mathrm{~mL}$ of $\mathrm{NaOH}$ solution $(0.05-0.4 \mathrm{M})$ were added to the loaded particles $(0.1 \mathrm{~g})$. The samples were stirred at $400 \mathrm{rpm}$ at room temperature $\left(20 \pm 1^{\circ} \mathrm{C}\right)$ for $2 \mathrm{~h}$. Then the samples were centrifuged and the supernatant was analyzed for arsenate. Regeneration efficiency was calculated.

\section{Results and discussion}

\subsection{Characterizations of RM and MRM}

SEM provides visual evidence of the effect of $\mathrm{FeCl}_{3}$ on the RM surface erosion and collapse. The exterior roughened and new cavities appeared during the modification process. The generation of new surface area by acidification was observed from the difference between the SEM of the RM and MRM samples (Fig. 1). The single-point $\mathrm{N}_{2}$-BET method indicated that the specific surface areas of the RM and MRM samples are about $115 \mathrm{~m}^{2} / \mathrm{g}$ and $192 \mathrm{~m}^{2} / \mathrm{g}$, respectively, which demonstrates that treatment with $\mathrm{FeCl}_{3} \cdot 6 \mathrm{H}_{2} \mathrm{O}$ increases the surface areas of 
(a)

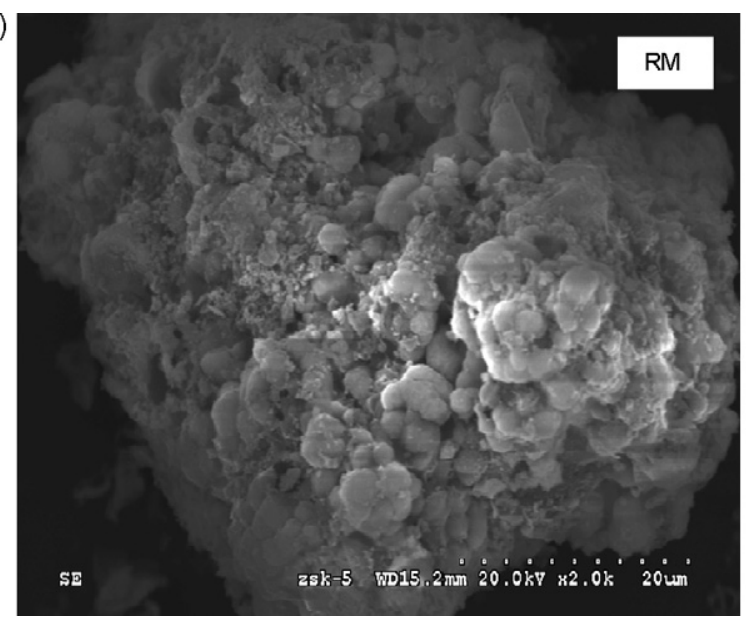

(b)

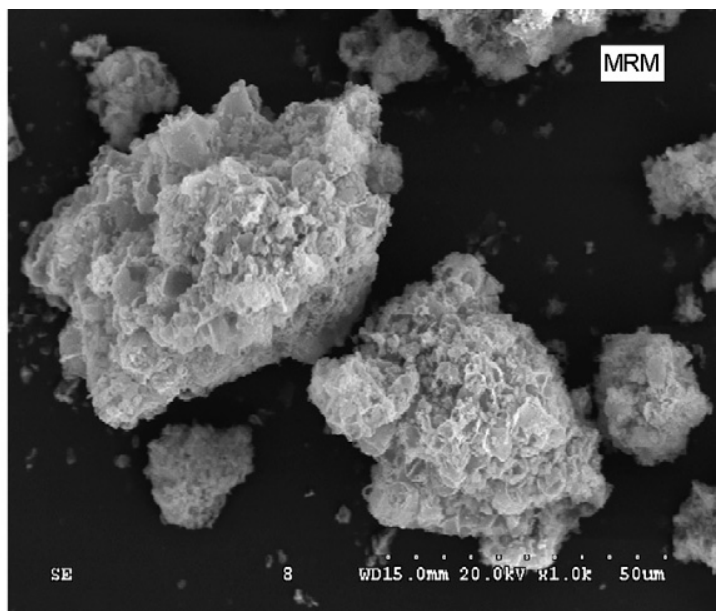

Fig. 1. SEM micrograph of the particles of the RM and MRM: (a) RM and (b) MRM.

the RM samples. After modification, the content of Fe in RM increased and calcium decreased as we can see from the element microanalysis report (Fig. 2). The wt.\% of Fe and Ca in RM were $10.6 \%$ and $4.2 \%$. After modification, the wt. $\%$ of $\mathrm{Fe}$ and $\mathrm{Ca}$ in MRM were $17.5 \%$ and $2.0 \%$, respectively. The results of X-ray analysis of RM and MRM were shown in Fig. 3. It revealed that the peaks of calcite, sodalite and quartz were reduced after modification.

(a)
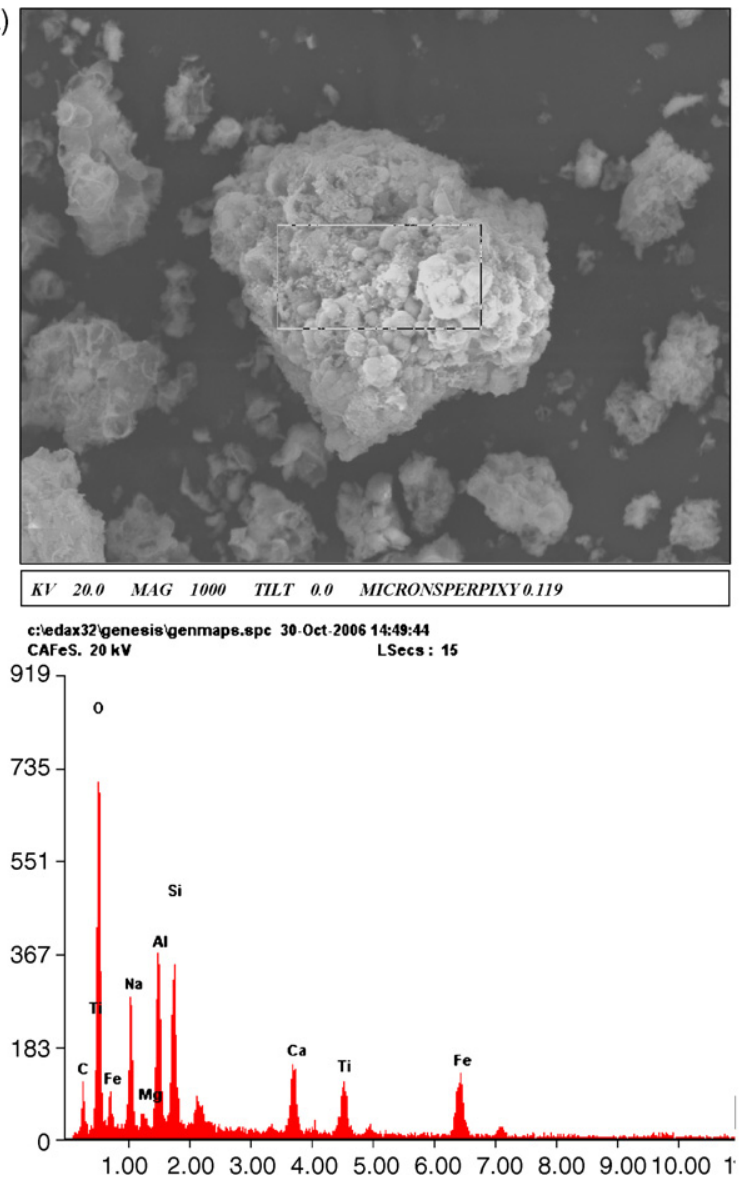

\subsection{Adsorption of arsenate on MRM}

\subsubsection{Kinetic study}

The effect of time on the removal of arsenate was investigated as described in sorption studies for increasing periods of time, until equilibrium was achieved. The removal of arsenate versus time was illustrated in Fig. 4a. The removal of $\mathrm{As}(\mathrm{V})$ increased with time and attained equilibrium at $24 \mathrm{~h}$ for the initial arsen-
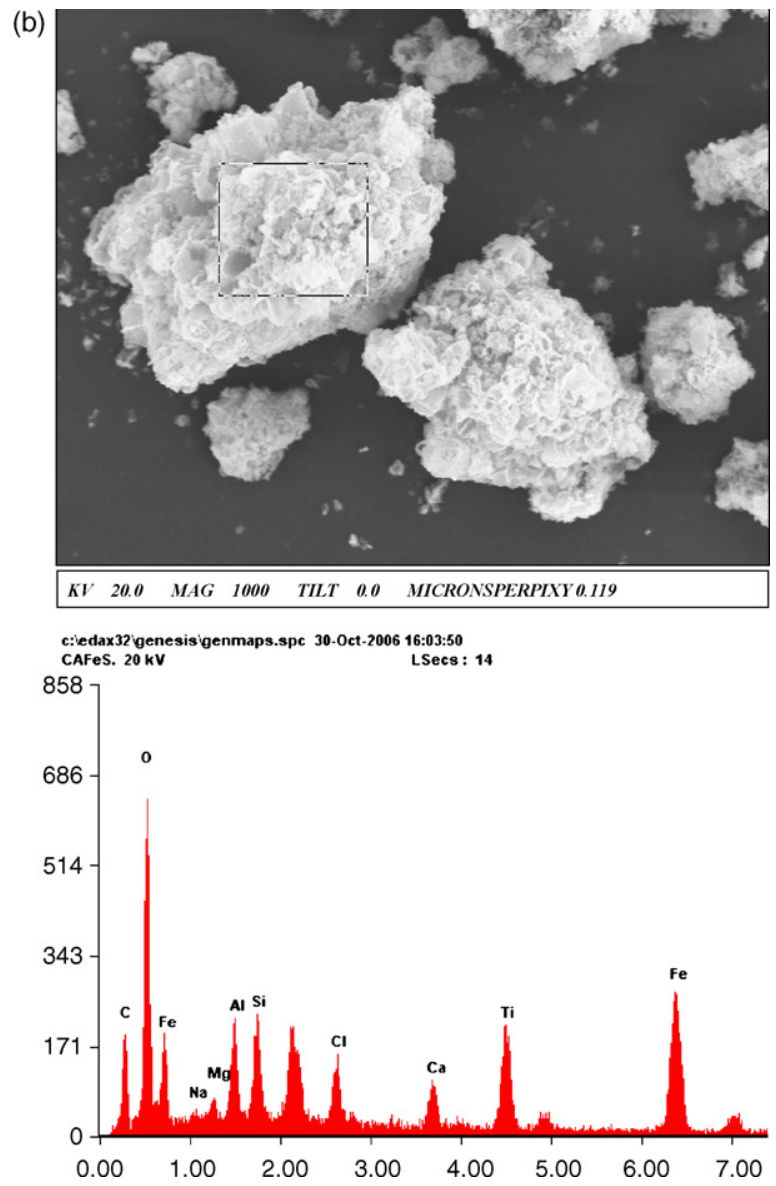

Fig. 2. Microanalysis report of RM (a) and MRM (b). 

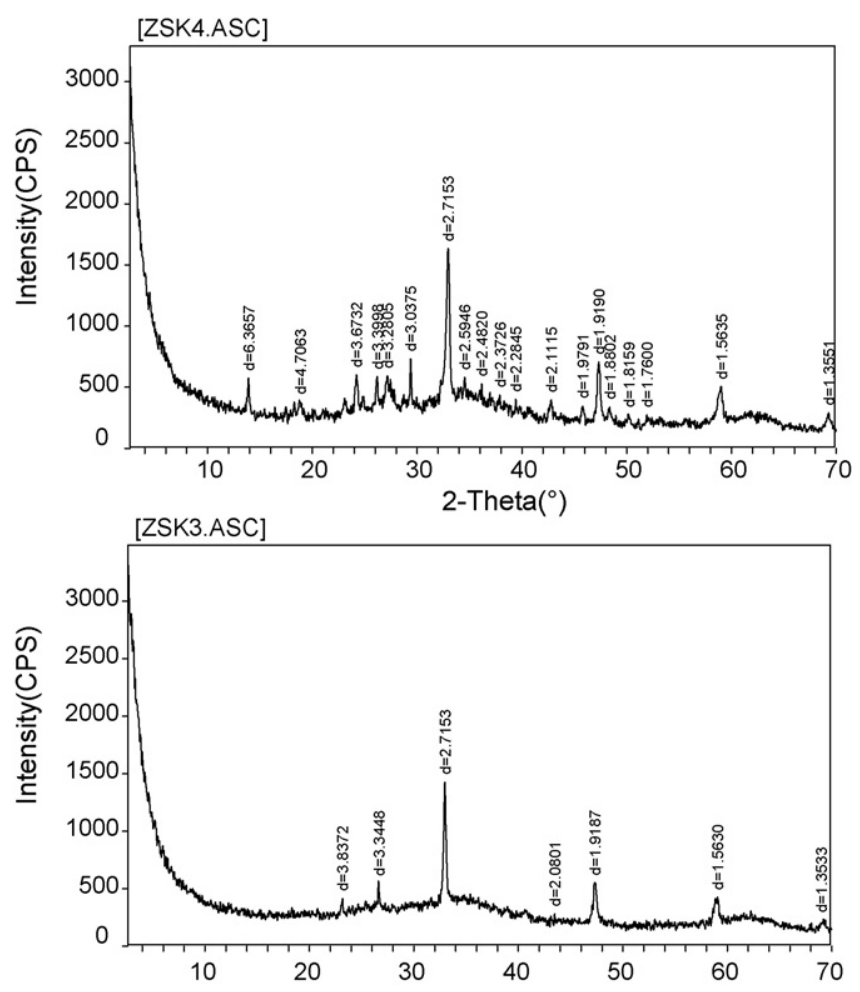

Fig. 3. XRD pattern of RM (a) and MRM (b).

ate concentration of $1 \mathrm{mg} / \mathrm{L}$. About $40 \%$ removal was achieved within the first 3 min and there was no significant change in the concentration after $24 \mathrm{~h}$.

The kinetic data obtained were analyzed by applying the pseudo-second-order kinetics model, which is expressed as (2):

$\frac{\mathrm{d} q_{t}}{\mathrm{~d} t}=k_{2}\left(q_{\mathrm{e}}-q_{t}\right)^{2}$

Linearized form of Eq. (2) is Eq. (3):

$\frac{t}{q_{t}}=\frac{1}{k_{2} q_{\mathrm{e}}^{2}}+\frac{t}{q_{\mathrm{e}}}$

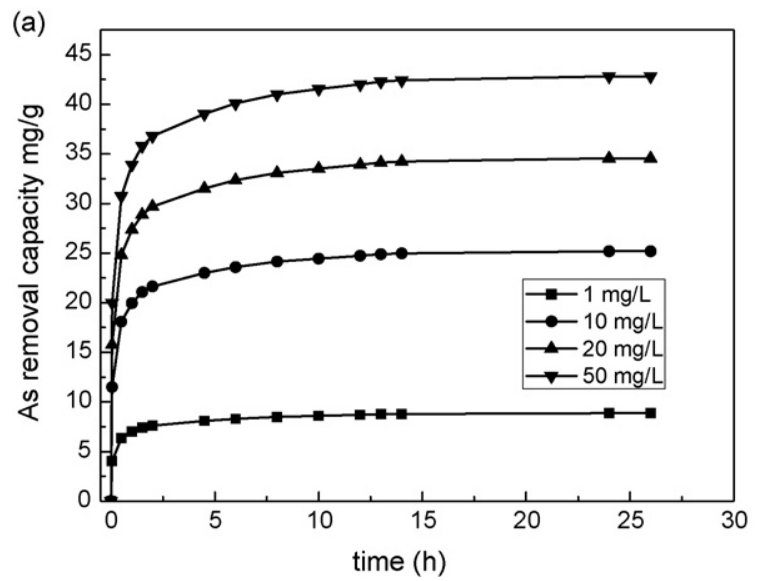

Table 2

Pseudo-second-order kinetics constants and related regression coefficients

\begin{tabular}{llll}
\hline As $(\mathrm{mg} / \mathrm{L})$ & $q_{\mathrm{e}}$ & $K_{2}\left(\times 10^{-3} \mathrm{~g}(\mathrm{mg} \min )\right)$ & $R^{2}$ \\
\hline 1 & 8.95 & 5.87 & 0.999 \\
10 & 25.46 & 2.07 & 0.999 \\
20 & 34.92 & 1.51 & 0.991 \\
50 & 43.25 & 1.22 & 0.998 \\
\hline
\end{tabular}

where $k_{2}(\mathrm{~g} /(\mathrm{mg} \mathrm{min}))$ is the pseudo-second-order kinetics constant, $q_{t}$ the amount of metal adsorbed per unit mass of adsorbent at $t$ (time) and $q_{\mathrm{e}}(\mathrm{mg} / \mathrm{g})$ is the amount of metal adsorbed per unit mass of adsorbent at equilibrium.

The statistical data have shown a fair goodness of correlation for pseudo-second-order kinetics (Fig. 4b). After the application of the pseudo-second-order kinetics model, the results were listed in Table 2.

\subsubsection{Effect of $p H$}

The $\mathrm{pH}$ of the aqueous solutions is an important variable and controls the adsorption between the adsorbent and aqueous interface. The extent of adsorption of anions is strongly governed by the $\mathrm{pH}$ of the solution [21-24]. The effects of the solution $\mathrm{pH}$ on arsenate removal were studied by varying the $\mathrm{pH}$ of the solution over a range of 3-10 using either $0.1 \mathrm{M} \mathrm{HCl}$ or $0.1 \mathrm{M} \mathrm{NaOH}$. The results depicted in Fig. 5 showed that arsenate removal was favoured at lower $\mathrm{pH}$ values for MRM. This kurtosis distribution was similar to the effect of $\mathrm{pH}$ on arsenic adsorption with seawater neutralized red mud [12], acid treated red mud [11,19] and sand-red mud columns [25]. Increasing arsenate adsorption with decreasing $\mathrm{pH}$ indicates the presence of fewer $\mathrm{OH}^{-}$ ions at lower $\mathrm{pH}$ conditions that can compete with the arsenate anions for the available sorption sites. Red mud is a metal oxide adsorbent containing different metal oxide in the structure. Hydroxylated surfaces of these oxides developed charge on the surface in water. The interaction between arsenate ion and metal oxide was modeled by assuming ligand exchange reactions as follows:

$\equiv \mathrm{M}-\mathrm{OH}+\mathrm{A}^{-}+\mathrm{H}^{+} \rightleftharpoons \equiv \mathrm{M}-\mathrm{A}+\mathrm{H}_{2} \mathrm{O}$

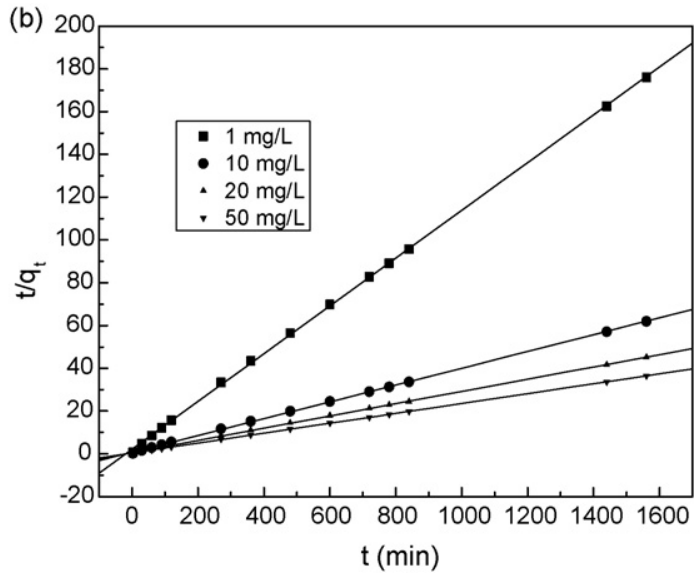

Fig. 4. Adsorption kinetics for arsenate removal using MRM. (a) Removal of arsenate as a function of equilibrium time and (b) pseudo-second-order kinetics plots with reaction conditions $I=0.01 \mathrm{M} \mathrm{NaCl}, \mathrm{pH} 6.8$, initial arsenate concentration $1 \mathrm{mg} / \mathrm{L}, 10 \mathrm{mg} / \mathrm{L}, 20 \mathrm{mg} / \mathrm{L}, 50 \mathrm{mg} / \mathrm{L}$, and MRM dosage is $100 \mathrm{mg} / \mathrm{L}$. 


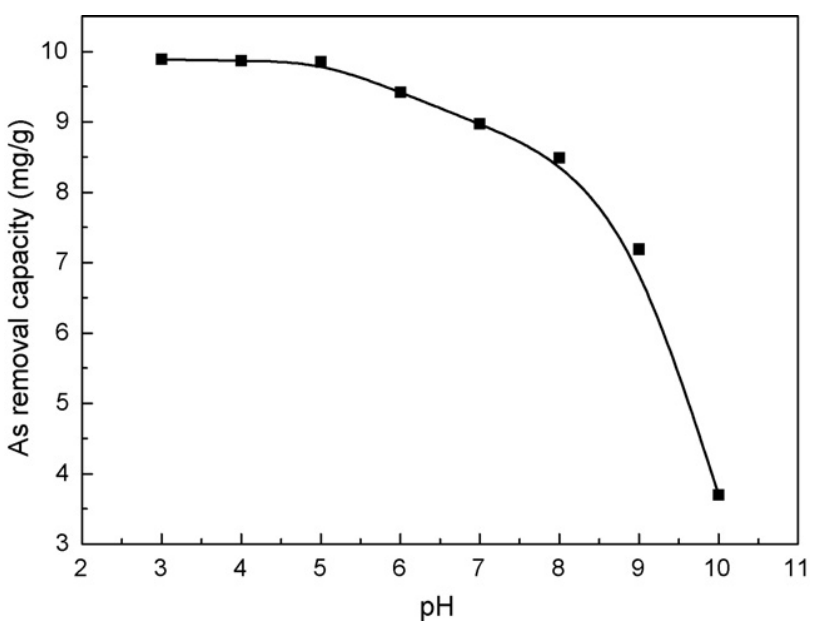

Fig. 5. Effect of $\mathrm{pH}$ on arsenate removal using MRM at room temperature with reaction conditions $I=0.01 \mathrm{M} \mathrm{NaCl}$, initial arsenate concentration $1 \mathrm{mg} / \mathrm{L}$ and dosage $100 \mathrm{mg} / \mathrm{L}$.

where $\mathrm{M}-\mathrm{OH}$ is a surface hydroxyl group and $\mathrm{M}-\mathrm{A}$ is the adsorbed species. According to Deliyanni [10] and Pedersen's [26] report, a strong adsorption of arsenate occurs on the $\mathrm{Fe}, \mathrm{Al}$ sites and $\mathrm{Fe}, \mathrm{Al}$ oxides are effective sites for arsenate adsorption. MRM is a mixture of $\mathrm{Fe}, \mathrm{Al}$ oxides and similar adsorption behavior happened.

\subsubsection{Adsorption isotherm}

In Fig. 6, the adsorption capacity of arsenate for different $\mathrm{As}(\mathrm{V})$ concentration at $\mathrm{pH} 6,7$ and 9 were presented. The Langmuir and Freundlich isotherm models were used to analyze adsorption data. The Langmuir equation was applied for adsorption equilibrium as follows:

$\frac{C_{\mathrm{e}}}{Q_{\mathrm{e}}}=\frac{1}{Q_{0} b}+\frac{C_{\mathrm{e}}}{Q_{0}}$

where $C_{\mathrm{e}}$ is the equilibrium concentration $(\mathrm{mg} / \mathrm{L}), Q_{\mathrm{e}}$ the amount adsorbed under equilibrium $(\mathrm{mg} / \mathrm{L}), Q_{0}(\mathrm{mg} / \mathrm{g})$ the theoreti-

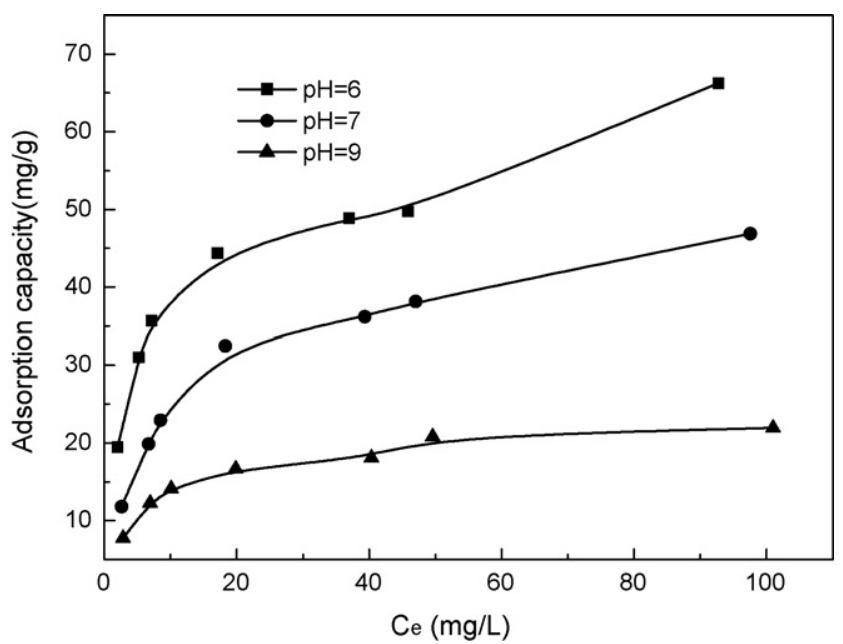

Fig. 6. Arsenate adsorption on MRM at room temperature with reaction conditions $I=0.01 \mathrm{M} \mathrm{NaCl}$, initial arsenate concentration range $2-100 \mathrm{mg} / \mathrm{L}$, and dosage $100 \mathrm{mg} / \mathrm{L}$.

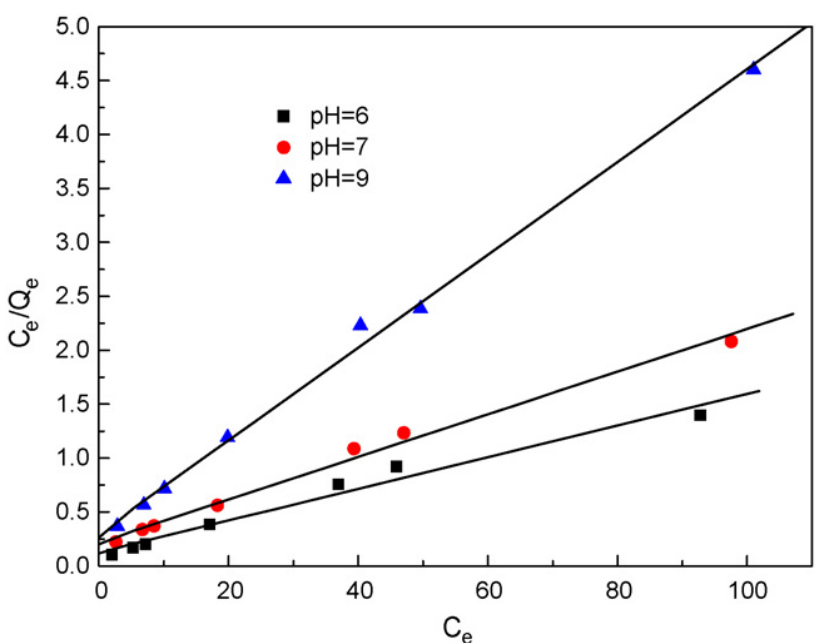

Fig. 7. Langmuir adsorption plots for arsenate adsorption on MRM at room temperature.

cal maximum adsorption capacity, and $b(\mathrm{~L} / \mathrm{mg})$ is a Langmuir constant related to the enthalpy of adsorption. $Q_{0}$ and $b$ are determined from the slope and intercept of the plot. The linear plots of $1 / Q_{\mathrm{e}}$ versus $1 / C_{\mathrm{e}}$ were obtained with $R^{2} \geq 0.98$ for various $\mathrm{pH}$, indicating that adsorption of $\mathrm{As}(\mathrm{V})$ onto MRM obeyed the Langmuir isotherm model. Plots fitted by the Langmuir equation for the three-tested $\mathrm{pH}$ were presented in Fig. 7. Adsorption capacity of the MRM was found to be $68.5 \mathrm{mg} / \mathrm{g}, 50.6 \mathrm{mg} / \mathrm{g}$ and $23.2 \mathrm{mg} / \mathrm{g}$ at $\mathrm{pH} 6,7$ and 9, respectively.

On the other hand, the Freundlich isotherm model could be expressed as follows:

$\log Q_{e}=\log K_{\mathrm{f}}+\frac{1}{n} \log C_{\mathrm{e}}$

where $K_{\mathrm{f}}$ and $n$ are empirical constants, being indicative of the extent of the adsorption and the degree of nonlinearity between solution concentration and adsorption, respectively. Plots fitted by the Freundlich equation for the three-tested $\mathrm{pH}$ were presented in Fig. 8.

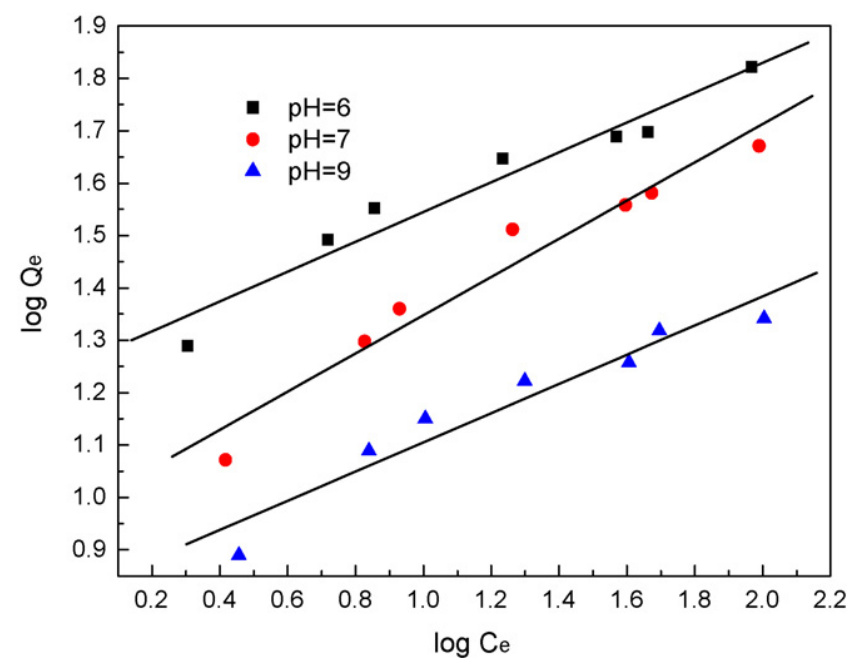

Fig. 8. Freundlich adsorption plots for arsenate adsorption on MRM at room temperature. 
Table 3

Calculated Langmuir and Freundlich isotherm parameters for arsenate adsorption on MRM (dosage $100 \mathrm{mg} / \mathrm{L}$ for $\mathrm{pH} \mathrm{6,7}$ and 9)

\begin{tabular}{llllllll}
\hline $\mathrm{pH}$ & \multicolumn{2}{l}{ Langmuir model } & & \multicolumn{3}{l}{ Freundlich model } \\
\cline { 2 - 3 } \cline { 7 - 8 } & $Q_{0}(\mathrm{mg} / \mathrm{g})$ & $R^{2}$ & $b(\mathrm{~L} / \mathrm{mg})$ & & $k$ & $R^{2}$ & $1 / n$ \\
\hline 6 & 68.5 & 0.980 & 0.114 & & 18.2 & 0.948 & 0.285 \\
7 & 50.6 & 0.991 & 0.090 & & 9.61 & 0.953 & 0.365 \\
9 & 23.2 & 0.996 & 0.142 & & 6.7 & 0.928 & 0.279 \\
\hline
\end{tabular}

Table 3 listed the calculated Langmuir and Freundlich constants, as well as the correlation coefficients of the respecting straight lines. A linear plot of $\log Q_{\mathrm{e}}$ versus $\log C_{\mathrm{e}}$ was also obtained with a $R^{2}>0.94$, showing that the adsorption followed the Freundlich isotherm model as well.

\subsubsection{Effect of coexisting ions}

$\mathrm{Ca}^{2+}, \mathrm{HCO}_{3}{ }^{-}$and $\mathrm{NO}_{3}{ }^{-}$always exist in natural water. In order to assess the potential applicability of MRM as the removal of arsenate from natural water, adsorption capacity was evaluated as a function of $\mathrm{Ca}^{2+}, \mathrm{HCO}_{3}{ }^{-}$and $\mathrm{NO}_{3}{ }^{-}$concentration. $\mathrm{NaHCO}_{3}, \mathrm{Ca}\left(\mathrm{NO}_{3}\right)_{2}$ and $\mathrm{NaNO}_{3}$ solutions were used in the experiment. Adsorption studies were carried out without adjustment and the $\mathrm{pH} 7.3$ of the mixture was measured. The results were shown in Fig. 9. $\mathrm{Ca}^{2+}$ significantly enhanced the adsorption capacity of MRM. An increase from $0 \mathrm{mg} / \mathrm{L}$ to $40 \mathrm{mg} / \mathrm{L}$ in the concentration of $\mathrm{Ca}^{2+}$ resulted in an increase from $8.5 \mathrm{mg} / \mathrm{g}$ to $9.5 \mathrm{mg} / \mathrm{g}$ in the amount of arsenate adsorbed. $\mathrm{Ca}^{2+}$ can link the MRM particle with arsenate, forming a metal-arsenate complex or a metal- $\mathrm{H}_{2} \mathrm{O}$-arsenate complex [27]. $\mathrm{HCO}_{3}{ }^{-}$decreased the arsenate removal efficiency. This is maybe due to the competition between $\mathrm{HCO}_{3}{ }^{-}$and $\mathrm{HASO}_{4}{ }^{2-}$ for positively charged adsorption sites. $\mathrm{NO}_{3}{ }^{-}$had no obvious effect on adsorption of arsenate because it did not compete with $\mathrm{HASO}_{4}{ }^{2-}$.

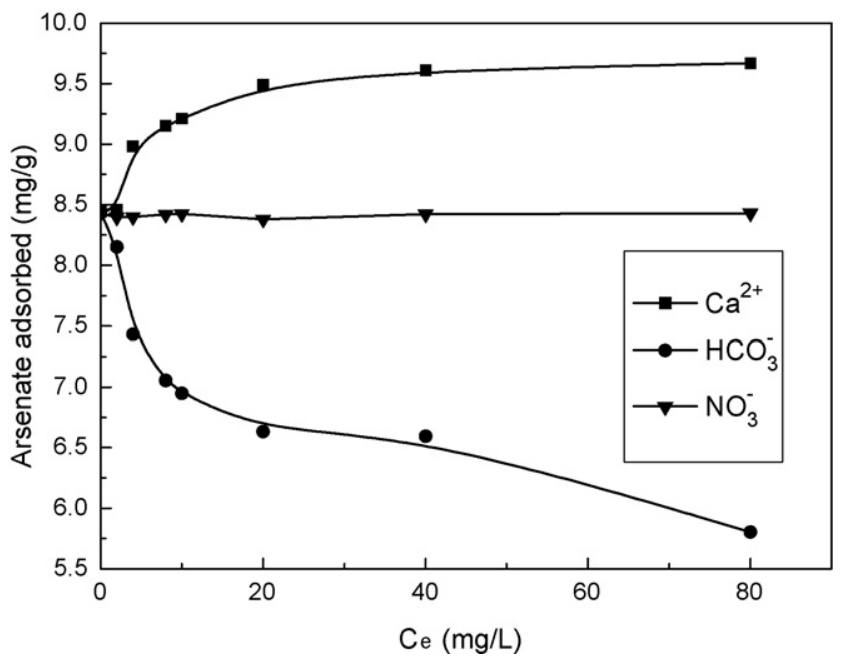

Fig. 9. Effects of the presence of ions on arsenate removal using MRM at room temperature with reaction conditions $I=0.01 \mathrm{M} \mathrm{NaCl}, \mathrm{pH} 7.3$, initial arsenate concentration $1 \mathrm{mg} / \mathrm{L}$, and dosage $100 \mathrm{mg} / \mathrm{L}$.

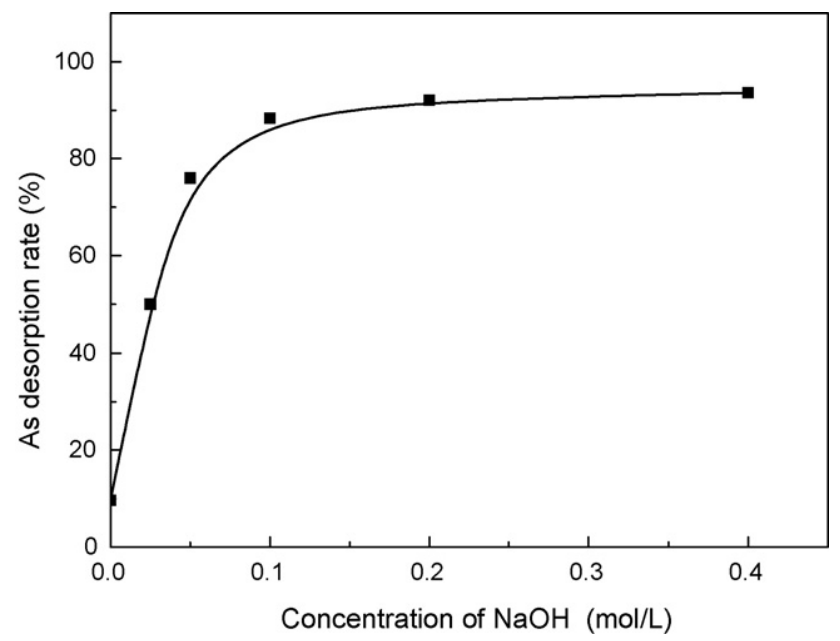

Fig. 10. Effect of $\mathrm{NaOH}$ concentration on desorption of arsenate.

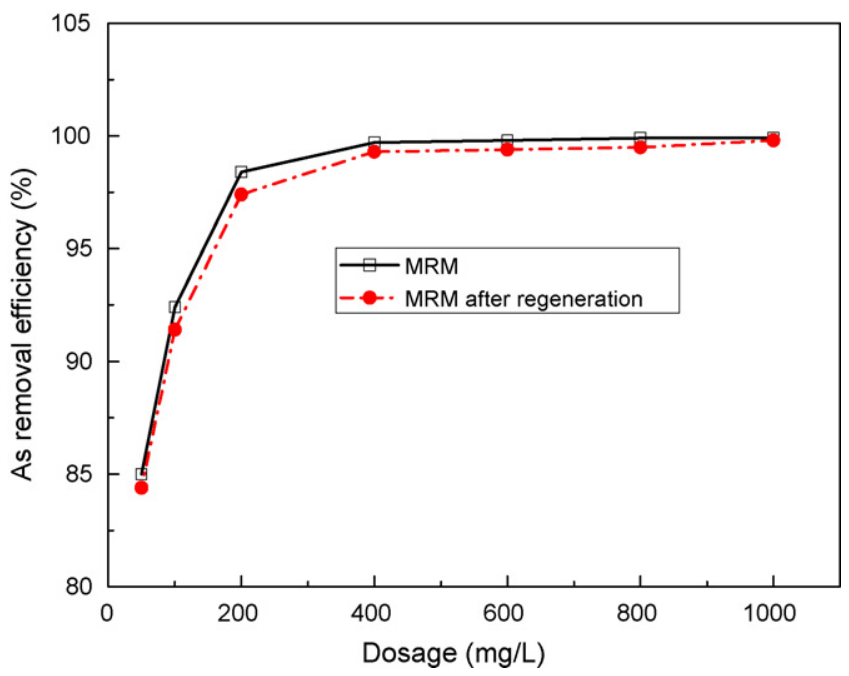

Fig. 11. Effect of the dosage on arsenate removal using MRM and MRM after regeneration at room temperature with reaction conditions $I=0.01 \mathrm{M} \mathrm{NaCl}, \mathrm{pH}$ 6 , initial arsenate concentration $1 \mathrm{mg} / \mathrm{L}$.

\subsection{Desorption}

The applicability of MRM as a potential adsorbent depends on the desorption property and reusability also. $\mathrm{NaOH}$ solution was selected as the regeneration agent. The effect of $\mathrm{NaOH}$ concentration on desorption efficiency was plotted in Fig. $10 . \mathrm{NaOH}$ was efficient for the MRM. The regeneration efficiency reached $88.4 \%$ and $92.1 \%$ when the concentration of $\mathrm{NaOH}$ reached $0.1 \mathrm{~mol} / \mathrm{L}$ and $0.2 \mathrm{~mol} / \mathrm{L}$, respectively. Comparative experiment of MRM and MRM after regeneration was carried out. Effect of the dosage on arsenate removal using MRM and MRM after regeneration was investigated. As seen from Fig. 11, the adsorption capacity of adsorbent after regeneration was equal to the MRM untapped.

\section{Conclusions}

Fe modified RM was successfully prepared and was reported to be an effective adsorbent for the removal of arsenate from 
water. The specific area of MRM reaches $192 \mathrm{~m}^{2} / \mathrm{g}$. The adsorption properties of MRM depend on $\mathrm{pH}$ values. It is effective for the removal of arsenate with a high capacity of $68.5 \mathrm{mg} / \mathrm{g}$. It has a much higher adsorption capacity than RM. Adsorption is favoured under acid conditions and the adsorption capacity increases with decreasing $\mathrm{pH}$. Adsorption is dependent on ionic strength. The adsorption increases in the presence of $\mathrm{Ca}^{2+}$, while $\mathrm{NO}_{3}{ }^{-}$has little effect and $\mathrm{HCO}_{3}{ }^{-}$decreases the adsorption. As can be desorbed from MRM with $\mathrm{NaOH}$ and the removal efficiency reaches $92.1 \%$ when the concentration of $\mathrm{NaOH}$ is $0.2 \mathrm{~mol} / \mathrm{L}$. The adsorption capacity of adsorbent after regeneration was equal to the MRM untapped.

\section{Acknowledgements}

The Key Technologies R\&D Programme of China supported this work. The authors thank Research Institute of Shandong Aluminium for providing the raw red mud.

\section{References}

[1] J. Matschullat, Arsenic in the geosphere-a review, Sci. J. Total Environ. 249 (2000) 297-312.

[2] Y. Zhang, M. Yang, X. Huang, Arsenic (V) removal with a Ce(IV)-doped iron oxide adsorbent, Chemosphere 51 (2003) 945-952.

[3] S.R. Cao, The survey of inorganic arsenic contamination in China, Chin. J. Public Health (15) (1996) 6-10.

[4] F.-S. Zhang, H. Itoh, Iron oxide-loaded slag for arsenic removal from aqueous system, Chemosphere 60 (2005) 319-325.

[5] B. Han, T. Runnellsb, J. Zimbronb, R. Wickramasinghe, Arsenic removal from drinking water by flocculation and microfiltration, Desalination 145 (2002) 293-298.

[6] S. McNeill, M. Edwards, Predicting arsenic removal during metal hydroxide precipitation, J. Am. Water Works Assoc. 89 (1997) 75-82.

[7] P.R. Kumar, S. Chaudhari, K.C. Khilar, S.P. Mahajan, Removal of arsenic from water by electrocoagulation, Chemosphere 55 (2004) 1245-1252.

[8] G. Ghurye, L. Clifford, D.A. Tripp, Combined arsenic and nitrate removal by ion exchange, J. Am. Water Works Assoc. 91 (10) (1999) 85-96.

[9] B.E. Reed, R. Vaughan, L.Q. Jiang, As(III), As(V), Hg, and Pb removal by Fe-oxide impregnated activated carbon, J. Environ. Eng. 126 (9) (2000) 869-873.
[10] E.A. Deliyanni, D.N. Bakoyannakis, Sorption of $\mathrm{As}(\mathrm{V})$ ions by akaganeitetype nanocrystals, Chemosphere 50 (2003) 155-163.

[11] H.S. Altundog, S. Altundog, F. Tumen, M. Bildik, Arsenic adsorption from aqueous solutions by activated red mud, Waste Manage. 22 (2002) 357-363.

[12] H. Genç-Fuhrman, J.C. Tjell, D. McConchie, O. Schuiling, Adsorption of arsenate from water using neutralized red mud, J. Colloid Interf. Sci. 264 (2) (2003) 327-334.

[13] L.Y. Li, A study of iron mineral transformation to reduce red mud tailings, Waste Manage. 21 (2001) 525-534.

[14] T. Phenrat, T.F. Marhaba, M. Rachakornkij, A SEM and X-ray study for investigation of solidified/stabilized arsenic-iron hydroxide sludge, J. Hazard. Mater. B 118 (2005) 185-195.

[15] P.K. Dutta, A.K. Ray, V.K. Sharma, F.J. Millero, Adsorption of arsenate and arsenite on titanium dioxide suspensions, J. Colloid Interf. Sci. 278 (2004) 270-275.

[16] Y.Çengeloğlu, E. Kır, M. Ersöz, Removal of fluoride from aqueous solution by using red mud, Sep. Purif. Technol. 28 (2002) 81-86.

[17] M. Erdem, H.S. Altundoğan, F. Tümen, Removal of hexavalent chromium by using heat-activated bauxite, Min. Eng. 17 (9-10) (2004) 1045-1052.

[18] H.S. Altundoğan, F. Tümen, Removal of phosphates from aqueous solutions by using bauxite II: the activation study, J. Chem. Technol. Biotechnol. 78 (2003) 824-833.

[19] S. Wang, Y. Boyjoo, A. Choueib, Z.H. Zhu, Removal of dyes from aqueous solution using fly ash and red mud, Water Res. 39 (2005) 129-138.

[20] L. Voinovitch, J. Debrad-Guedon, J. Louvrier, The Analysis of Silicates, Israel Program for Scientific Translations, Jerusalem, 1966, pp. 127-129.

[21] H. Genç-Fuhrman, J.C. Tjell, D. McConchie, Increasing the arsenate adsorption capacity of neutralized red mud (Bauxsol), J. Colloid Interf. Sci. 271 (2004) 313-320.

[22] S. Goldberg, C.T. Johnston, Mechanisms of arsenic adsorption on amorphous oxides evaluated using macroscopic measurements, vibrational spectroscopy, and surface complexation modeling, J. Colloid Interf. Sci. 234 (1) (2001) 204-216.

[23] S.K. Gupta, K.Y. Chen, Arsenic removal by adsorption, J. Water Pollut. Control Fed. 50 (3) (1978) 493-505.

[24] M.L. Pierce, C.B. Moore, Adsorption of arsenite and arsenate on amorphous iron hydroxide, Water Res. 16 (1982) 1247-1253.

[25] H. Genç-Fuhrman, H. Bregnhøj, D. McConchie, Arsenate removal from water using sand-red mud columns, Water Res. 39 (2005) 2944-2954.

[26] H.D. Pedersen, D. Postma, R. Jakobsen, Release of arsenic associated with the reduction and transformation of iron oxides, Geochim. Cosmochim. 70 (2006) 4116-4129.

[27] X. Peng, Z. Luan, F. Chen, B. Tian, Z. Jia, Adsorption of humic acid onto pillared bentonite, Desalination 174 (2005) 135-143. 